\title{
Segovia en la Alta Edad Media. Una aproximación a su estructura urbana.
}

\author{
Segovia in Early Middle Age. \\ Approach to urban structure
}

Miguel Ángel Martín Blanco

Arquitecto. Doctorando ETSAM. Universidad Politécnica de Madrid.

martinblanco.miguel@gmail.com

Recibido: 21/01/2016

Aceptado: 30/03/2016

\begin{abstract}
Resumen
El proceso de formación de la estructura urbana del recinto amurallado de Segovia está estudiado a partir de la Repoblación oficial de la ciudad ordenada en 1088 por el Rey Alfonso VI, poco después de la conquista de Toledo. Sin embargo numerosos estudios apoyan la hipótesis de la continuidad poblacional durante la Alta Edad Media, dando por sentado que la ciudad ya estaba habitada antes de esa Repoblación. A través del análisis de diferentes evidencias urbanas, arquitectónicas y arqueológicas creemos demostrar la existencia de dos tipos de urbanismo diferenciados, aportando una primera aproximación a la configuración de la ciudad en la Alta Edad Media.
\end{abstract}

\section{Palabras clave}

Segovia, Alta Edad Media, Historia de la ciudad, Arqueología urbana, Repoblación, muralla. 


\begin{abstract}
The process of formation of the urban structure of Segovia's walledtown is studied from the Official repopulation of the city in 1088 ordered by King Alfonso VI, shortly after the conquest of Toledo. But numerous studies support the hypothesis of continuity the population during the Early Middle Age and accepting that the city was already inhabited before this repopulation. Through the analysis of various urban, architectural and archaeological evidence we prove the existence of two distinct types of urban planning, providing a first approach to the configuration of the city in the Early Middle Age.
\end{abstract}

\title{
Keywords
}

Segovia, Early Middle Age, Urban History, Urban Archaeology, Repopulation, City Wall.

Referencia normalizada: MARTín BlANCO, Miguel Ángel (2016): “Segovia en la Alta Edad Media. Una aproximación a su estructura urbana". Arte y Ciudad. Revista de Investigación, no 9 (abril), págs. 105-134. Madrid. Grupo de Investigación Arte, Arquitectura y Comunicación en la Ciudad Contemporánea, Universidad Complutense de Madrid.

Sumario: 1.- Introducción. 2.- Las evidencias de la ciudad de Segovia en la Alta Edad Media. 3.- Los edificios de la Repoblación oficial. 4.- El análisis de la estructura urbana. 4.1. El trazado de las calles y sus plazas. 4.2. La morfología de las manzanas y la tipología de las parcelas. 5.- La ciudad de la Repoblación oficial. 6.- Bibliografía.

\section{Introducción.}

El presente artículo pretende profundizar en el conocimiento de la estructura urbana de la ciudad amurallada de Segovia antes de que se configure su trazado y forma actual, que ocurre en el siglo XVI (Martínez Pisón, 1976: 53), culminando un proceso que se inicia con la Repoblación oficial a partir de 1088, encomendada a Raimundo de Borgoña, por el rey Alfonso VI poco después de la conquista de Toledo.

El viario estaba bastante constituido desde época temprana, y no solo se demuestra por el aspecto, las parroquias ya existentes y la documentación en general, sino por la no frecuente abundancia relativa a edificaciones civiles románicas subsistentes. Iglesia y caballeros fueron, según parece, las principales fuerzas motrices de este rápido desarrollo del espacio nuclear (Montero Vallejo, 1996: 206). 
Con estas palabras se refiere Montero Vallejo a la ciudad de Segovia, señalando que el recinto amurallado era la zona residencial de la nobleza y la Iglesia, mientras que las clases trabajadoras se asentaban mayoritariamente en los arrabales extramuros.

A lo largo de los siglos, esta parte de la ciudad ha sufrido diversas transformaciones en su trama urbana, especialmente a lo largo del XIX y principios del $X X$, pero abstrayéndonos de la configuración actual de los edificios y especialmente sus fachadas, habitualmente transformadas, enmascaradas o sustituidas, podemos encontrar algunos elementos invariables o menos alterados, que aportan unas pautas que nos permiten leer la evolución histórica urbana.

Es posible que los datos tomados para elaborar esta hipótesis urbana pertenezcan a realidades y momentos históricos distintos, a pesar de su aparente coherencia. Por lo tanto, lo que se plantea es una hipótesis previa, abierta a modificaciones, sobre la que seguir trabajando. La aparición de nuevos restos arquitectónicos, ahora ocultos en los edificios y los hallazgos de nuevos datos que aporten las excavaciones arqueológicas permitirán, en un futuro, rechazar nuestra hipótesis, matizarla o confirmarla.

La estructura urbana posiblemente sea una de las huellas más perdurables en el tiempo. El trazado de las calles y plazas, la forma de las manzanas, las alineaciones y la disposición del parcelario o la implantación de los edificios históricos, como son sus murallas, sus iglesias, son difícilmente borrables, salvo grandes catástrofes. Estos son los tres aspectos fundamentales del urbanismo histórico que vamos a estudiar, la trama viaria, el parcelario y los edificios históricos, las principales herramientas de nuestro análisis, eminentemente gráfico, de la estructura urbana.

\section{Las evidencias de la ciudad de Segovia en la Alta Edad Media.}

Como se ha comentado anteriormente, la hipótesis generalmente aceptada emplaza el punto de partida del proceso de configuración urbana del recinto amurallado de la ciudad en la época cristiana, considerando que fue encomendada a Raimundo de Borgoña, quien se encargó de repoblar y fortificar la ciudad tras la toma de Toledo en el 1085 (Ruiz, 1982: 25), tal y como está documentado que ocurrió en Ávila (Montero Vallejo, 1996: 205), Zamora y Berlanga de Duero (Cooper, 2014: 63). 
Es evidente que en una ciudad como Segovia, ocupada por distintos pueblos a lo largo de los siglos, deben haber existido diversos trazados urbanos. De etapa romana y prerromana solo se intuye cual era la extensión de la ciudad gracias a los hallazgos arqueológicos, si bien no se ha profundizado sobre la posible estructura urbana de esa época (Marqués, 2009: 214), (Martínez, 2010: $143-181)^{1}$. De la etapa visigoda, disponemos de muy escasos datos documentales y aún menos arqueológicos ${ }^{2}$, pero estos parecen confirmar la continuidad poblacional de la ciudad.

En estadios más cercanos a la Repoblación, que es la etapa que nos va a interesar, a falta de datos documentales concretos relativos a la ciudad de Segovia $^{3}$, disponemos igualmente de resultados de prospecciones arqueológicas que aportan datos hasta la fecha inconexos faltos de un estudio de conjunto que los relacione. Así tenemos evidencias de numerosos enterramientos en los valles del Eresma y Clamores, datados en el siglo X (Zamora, 2010: 362-363), o la necrópolis de la iglesia de San Millán, datada entre los siglos IX y XIII (Zamora, 1979: 528-536), (Zamora, 1998: 33). Adosada a esta iglesia, encontramos una torre previa de posible adscripción mozárabe (Ruiz, 1973: 54), (Ruiz, 1988: 19), (Lojendio 1992: 231), (Merino de Cáceres, 2005), (Chaves, 2006: 174).

Ya dentro de las murallas se han descubierto en la iglesia de San Juan de los Caballeros restos de una iglesia del siglo VI, reformada en el $\mathrm{X}^{4}$ (Zamora,

\footnotetext{
${ }^{1}$ Los planteamiento de Martínez Caballero (2010) se han visto en parte ya superados por nuevos hallazgos arqueológicos que extienden la ciudad romana mucho más allá de lo que se suponía (Labrador, J.M, 2015).

2 Tenemos la constancia de la existencia y poblamiento de la ciudad de Segovia, ya que al ser una sede episcopal visigoda hay menciones de la asistencia de obispos segovianos a los distintos concilios que se convocan (Zamora, 1997: 422). Ilderedo, Obispo de Segovia, en el siglo X, tiene una residencia en León (Ruiz, 1973: 53).

${ }^{3}$ La ocupación real de las tierras de la Extremadura castellana por parte de las gentes venidas del norte es anterior a lo que se venía admitiendo. Existe constancia documental de donaciones territoriales a diversos monasterios efectuadas a principios del siglo X (Zamora, 1997: 418). Incluso afirma que a finales del siglo $X$ o principios del XI la zona está ya suficientemente poblada como para ser soporte de incursiones al sur (Zamora, 1997: 420).

${ }^{4}$ Bajo la actual iglesia de San Juan de los Caballeros existe una iglesia anterior, de planta basilical con cabecera de tres ábsides rectos, datada en el siglo VI. La planta de esta iglesia nos muestra un edificio de dimensiones muy considerables $(37 \times 15$ metros -exteriores- medidas sobre los planos del autor) lo que nos indica lo numerosa de la población segoviana intramuros en dicho siglo y la capacidad económica de ésta. Utrero Aguado (2006: 495) da unas dimensiones
} 
1979), (Zamora, 1997: 423), (Zamora, 1998: 11-15)5, al igual que en la iglesia de San Martín, se adivinan trazas de una iglesia previa, (Ruiz, 1973: 54) (Ruiz, 1988: 149) de estructura similar al Cristo de la Luz en Toledo (Lojendio, 1922: 255). Otros autores no aprecian estos indicios de iglesia previa (García Guinea, 2007: 1439). Por último, indicar que en las iglesias de San Nicolás y la Santísima Trinidad también se han encontrado restos de iglesias previas, aunque dichas preexistencias se consideran estilísticamente románicas (López-Ambite, 1995) (Zamora, 1998: 16) (García Guinea, 2007: 1421). Respecto a la iglesia de San Miguel, que estuvo hasta finales del siglo XV emplazada sobre la actual Plaza Mayor, Garci Ruiz de Castro (1551: 5) nos habla de la existencia en dicho solar de una ermita de la misma advocación, en cuyo lindero existían unas viñas, sobre la que se edifica la posterior iglesia románica.

Por lo tanto, las distintas pruebas apuntan a que existía un asentamiento habitado previo y esta última referencia nos permite imaginar una ciudad con escasa densidad y de aspecto rural. Esta superficie construida suponemos que presentaría posiblemente numerosas ruinas de edificios anteriores e importantes vacíos destinados a huertos, no sería un continuo edificado, sino posiblemente presentaría amplias discontinuidades entre las distintas colaciones que de forma autónoma se hubiesen conformado en torno a sus respectivas parroquias, San Juan de los Caballeros, San Martín, San Briz y San Gudumian ${ }^{6}$ o en

de 37 metros de largo y 14,80 metros de ancho. Comparando las dimensiones de ese edificio con los principales edificios religiosos pertenecientes a la etapa visigoda de los que tenemos evidencias, los datos son evidentes. San Juan de Baños, fechada en 661, mide $20 \times 15$ metros, lo mismo que San Pedro de la Nave, datada entre 680 y 711 o Santa Comba de Bande (año 672) de $22 \times 13$ metros. Aunque las medidas son aproximadas efectuadas sobre los planos de Chueca Goitia (1989: 15-20), la falta de exactitud de las mediciones queda justificada ya que la proporción indica que la iglesia segoviana es un $50 \%$ más grande que los otros ejemplos. A efectos de la comparación, la diferencia de magnitudes es tan abultada que no parece necesario afinar más la medición.

${ }^{5}$ La portada al sur, actualmente desplazada al transepto, la data del siglo $X$, así como algunos capiteles actualmente reutilizados en el ábside. "Viene a indicarnos que no solo existió población en esas fechas, sino que aquellas gentes mantuvieron la suficiente pujanza económica para acometer obras de cierta entidad en su iglesia. Son confirmación de otros datos que abundan en el mismo sentido, sobre la presencia de poblaciones, ya en estas tempranas fechas. Y ello ocurre bastante antes de que los textos permitan afirmarlo sin lugar a dudas" (Zamora, 1998: 14).

${ }^{6}$ Esta situación es común a toda Europa, no solo en las ciudades cristianas de la Península (Heers, 1978: 182). 
las proximidades de la ermita de San Miguel. La imagen de Segovia sería muy distinta a la de un recinto amurallado encerrando un continuo urbano completamente colmatado, siendo parecida a la de una pequeña aldea, o varias aldeas muy próximas entre sí, según la descripción que Idrisi hará de ella hacia $1150^{7}$.

Otras evidencias de la existencia de una ciudad previa a la Repoblación son los vestigios de carácter militar que se encuentran en el Alcázar (Ruiz, 1982, I: 29), (Ruiz, 2010: 45- 91), en las murallas con fragmentos de adscripción musulmana (Zozaya, 2005: 25) (Zamora, 1994 y 2005) (Martín Blanco, 2015) o en el convento de las dominicas, antiguo Palacio de Don Alimán, que si bien el conjunto interior es obra posterior (Ruiz, 1982, I: 47-48), su fachada para algunos autores es fábrica de aparejo hispanomusulmán (Zamora, 2008) lo que de ser cierto, nos aporta una de las escasas alineaciones urbanas conservadas previas a la Repoblación.

De la presencia musulmana en Segovia existen muy escasos testimonios materiales, una columna y un capitel de mármol de estilo califal, descubiertos en una casa del actual barrio de las Canonjías, que se encuentra en este momento en el museo Arqueológico Nacional de Madrid (Ruiz, 1973: 70) (Ruiz, 1986: 26) ${ }^{8}$. Posteriormente se ha encontrado otro capitel en el convento de las Oblatas (Zamora, 1997: 420). Esta ausencia de información se ve agravada por el escaso espesor del sustrato arqueológico en la mayor parte de la ciudad histórica de Segovia. En otras ciudades como León la ocupación islámica está perfectamente demostrada por las fuentes documentales y sin embargo no se ha encontrado ningún tipo de vestigios que lo atestigüe (Gutiérrez González, 1999: 53). Algo similar puede estar pasándonos en la ciudad de Segovia, si bien en nuestro caso, tampoco abundan las pruebas documentales que nos apoyen.

\footnotetext{
${ }^{7}$ La configuración rural o de las ciudades incipientes (primitiva) se caracteriza por un caserío ralo, formado por casas y corrales que se entremezclan con viñas, tierras y otras parcelas de usos agrícolas, donde la parte edificada es escasa y discontinua. Esto produce una configuración poco integrada, caracterizada por una morfología que desdibuja la malla callejera, reducida a caminos, callejas y callejones sin salida, sin una clara determinación, en la que se inserta una parcelación sumamente irregular, basada en los corrales heredados del mundo rural. (Crespo, 2007: 229).

${ }^{8}$ Posiblemente pertenezca a un edificio religioso. Incluye una inscripción que lo data en el año 960 (Gómez de Somorrostro, 1820: 234-238).
} 
Otros autores ven la presencia musulmana en la existencia de zarpas en las bases de algunas torres de la muralla entre la puerta de San Andrés y el postigo del Sol (Zozaya, 2005: 25), sin dar mayor desarrollo a la afirmación, y otros que profundizan en la presencia de restos de fortificaciones próximas, en la provincia de Segovia, como son Ayllón, Sepúlveda, Fuentidueña (Zamora, 2005: 1138), que se vinculan a Almanzor y al sistema defensivo de torres para la defensa de los pasos de la sierra (Zamora, 1997: 419).

Si existía una fortificación en el Alcázar antes de la Repoblación y la ciudad estaba habitada, estamos convencidos de que debería existir un acueducto subterráneo que suministrase a los aljibes y pozos de las viviendas, a las diversas fuentes que hubiese por la ciudad ${ }^{9}$ y llegase hasta esa fortificación, desde el tramo aéreo que permanece. Según los últimos estudios realizados en torno al canal del acueducto en su tramo urbano subterráneo, todos los hallazgos que se han efectuado corresponden a reformas efectuadas después de los Reyes Católicos, a partir del siglo $\mathrm{XV}^{10}$, hasta el punto de que hay autores que dudan de que el acueducto romano llegase hasta el alcázar (Martínez, 2012: 36-37).

No vamos a analizar si existía un acueducto romano subterráneo hasta el alcázar, pero estamos convencidos de que existía un abastecimiento de agua previo al actual. Creemos que lo que se hace en el siglo XV es una reparación, quizá completa, pero sobre el mismo trazado, ya que discurre por la cresta de la roca, el punto más alto, no hay posibilidad de un recorrido muy distinto del actual, para abastecer por gravedad a todo el recinto amurallado.

Evidentemente, tras la Repoblación de la ciudad el acueducto subterráneo está en funcionamiento, ya que las casas de las Canonjías disponen de abastecimiento de agua ya en el siglo XII (Ruiz 2005: 83). Sin embargo no existe ningún escrito que refiera a la reparación de tan importante obra hidráulica para su puesta en uso, ni durante la citada Repoblación, ni en reinados sucesivos,

\footnotetext{
${ }^{9}$ Del siglo XII solo está documentada la fuente de Santa María, cuya ubicación es incierta. Ruiz Hernando la sitúa en la plaza de la Merced, aunque se conoce la ubicación de muchas más, pero todas ellas datadas ya en la Baja Edad Media (Martínez, 2012: 156-157).

${ }^{10}$ Es una canalización tallada en la roca de unos 30x30 cm de sección y cota muy superficial, a escasos $50 \mathrm{~cm}$ de profundidad. Lo conservado en la calle Daoiz es obra del siglo XVI. Para más información, véase Martínez (2012) y (GROMA, 2011).
} 
hasta los Reyes Católicos, en que se acometen obras para reparar los desperfectos que existen en tan importante infraestructura.

En la calle Daoiz, eje principal del barrio de las Canonjías, el acueducto no discurre por el eje central de la calle. Por el contrario va cruzando de un lado a otro de la misma, acercándose a los edificios de ambos laterales (Groma, 2011). Este aparentemente errático trazado en relación con la alineación de los edificios, demuestra claramente que cuando se ejecuta la canalización los edificios no existían, y que la edificación se dispone después del trazado de la conducción de agua, a lo largo de una calle cuyo recorrido queda condicionado por este acueducto. El hecho de que la creación de este barrio esté palmariamente establecida poco después de la Repoblación Oficial y la conservación de varias de sus fachadas románicas originales nos evidencia el mantenimiento de las alineaciones primigenias de dicha Repoblación, creemos que nos muestra, que dicho trazado del acueducto es anterior a las alineaciones de la Repoblación. Además, el hecho de que en la razzia de 1071, Al-Mamun, rey de la taifa toledana, destruyese algunos de los arcos (Ruiz, 1982, I: 21), evidencia que el acueducto suministraba agua a la ciudad y que ésta estaba habitada antes de la Repoblación.

Por último, la toponimia facilita algunos datos, como por ejemplo las iglesias de advocación mozárabe, que presupone su existencia antes de la Repoblación, como son los casos de San Millán, San Gudumian, San Briz, San Martín (Zamora, 1997: 424) y San Cebrián, cuya ubicación nos sitúa sobre el plano Antonio Ruiz' ${ }^{11}$ (Ruiz, 1982, I: 79). También se ha incidido sobre la raigambre árabe del termino Almuzara ${ }^{12}$ que actualmente aún se conserva en la calle de

${ }^{11}$ De estas iglesias, las desaparecidas como San Gudumian, posteriormente llamada capilla de San Gregorio, se alzaba junto a la Casa del Sol, actual Museo de Segovia y antiguo Matadero Municipal, al comienzo de la Ronda de Juan II. San Briz se ubicaba en el solar que ocupó, en el siglo XVI, la cárcel Publica, y San Cebrián, este autor la relaciona con la iglesia de San Antón, ya que San Cebrián no vuelve a mencionarse en la documentación histórica y sí la de San Antón.

${ }_{12}$ Almuzara o musara era "un lugar para ejercicios ecuestres y esparcimiento público en las afueras de algunas ciudades musulmanas de occidente" (Torres Balbás, 1985, 126) Diversos autores coinciden en definiciones similares: "Área amplia destinada a los ejercicios de caballería y se practicaban diversas juegos y actividades al aire libre" (Betrán, 1992: 124). "Espacio extramurado para juegos de equitación y entretenimiento en la destreza de las armas" (Montero Vallejo, 1992: 88). También se considera que su nombre proviene de la designación árabe de un molino de aceite, “en tiempos de los judíos” (Sáez y Romero, 2009: 8). 
dicho nombre ${ }^{13}$ y que hace sospechar de la existencia de un amplio espacio libre urbano en las proximidades de la hoy plaza de San Andrés, (Ruiz, 1973: 57), del mismo modo que el término Azoguejo, también topónimo de origen árabe -Azogue pequeño- (Montero Reguera, 1999: 316), denota la permanencia y la continuidad poblacional en la ciudad de Segovia, previamente a la Repoblación oficial de Alfonso VI, asunto que creemos ya suficientemente demostrado y debatido ${ }^{14}$.

La pervivencia en Segovia de la toponimia de época visigoda hasta la actualidad, (de transmisión principalmente oral) refuerza la hipótesis de la continuidad poblacional (Hoz Onrubia, 2006: 60-89).

Reflejando todos estos datos sobre un plano de la ciudad de Segovia ${ }^{15}$ (figura 1), observamos que la dispersión y escasez de la información, aparentemente no nos facilitan mucha información, al presentar grandes vacíos que no permiten una interrelación clara de los escasos datos disponibles. Veremos como la superposición de las diferentes etapas históricas diferenciadas sí nos permite avanzar en el conocimiento de la estructura urbana de la ciudad de Segovia.

Lo significativo del caso segoviano es que se sitúa intramuros de la ciudad medieval. La musa$r a$, solo existía en las ciudades más importantes Si Segovia no se menciona entre las grandes ciudades y además, la musara se encuentra intramuros por lo que Torres Balbás no la considera musulmana (1985: 126).

${ }^{13}$ La primera referencia escrita es en el año 1152. “Aunque en Segovia extraña su localización en el interior de la muralla, entre la catedral y la plaza de San Andrés, confirma la relación que desde el siglo XIII se denomine "coso" o "tela", lugar donde se lidiaban los toros o se realizaban otras actividades deportivas" (Pérez, 1993: 30) Resultaba significativo que se haga referencia a que en ella existen casas y se sitúan en sus proximidades los corrales de Jençor, del Mudo, de Cayón, de la Poça y el de los Moros (Pérez, 1993: 34); (Ruiz, 1982, I: 35-36).

14 “En Segovia se produce una disminución poblacional, pero no una despoblación absoluta. Un estudio del entorno cercano de la ciudad de Segovia nos demuestra que la falta de documentos escritos supone falta de información (o de su estudio) pero no falta de población" (Alonso, 1989). "En base a la toponimia, se puede asegurar la continuidad poblacional a pesar de la ausencia de vestigios arqueológicos, que el tiempo y la búsqueda sistemática irán sin duda aportando en un futuro" (González y González, 1974). Otros estudios más recientes sobre el mismo tema en (Siguero, 1997), (Zozaya, 2005), (Barrio, 2010).

15 Para ello partiremos del plano elaborado por Antonio Ruiz (1982, I: 78) correspondiente a la Segovia del siglo XVIII, realizado en base a los datos obtenidos en el Catastro de Ensenada, [1752] sobre el que ya se presenta el trazado anterior a las reformas de Odriozola, reelaborado por nosotros, incluyendo las aportaciones que hemos comentado en el texto. Para el trazado del acueducto hemos tomado el del Martínez Caballero (2012: 150). 


\section{Los edificios de la Repoblación oficial.}

El urbanismo de la ciudad a partir del siglo XII está estudiado por Ruiz Hernando (1982), cuyo trabajo tomaremos como punto de partida. Así conocemos la ubicación de las principales iglesias que aparecen tras la Repoblación y el trazado del barrio de las Canonjías ${ }^{16}$ ejemplo del urbanismo medieval relativamente bien conservado, de indudable parcelación planificada y cronología claramente establecida, que conserva sus alineaciones prácticamente intactas desde la Repoblación.

El conjunto arquitectónico románico segoviano, o para ser más exactos, el datable tras la repoblación, desde finales del siglo XI hasta finales del XII, está compuesto por 14 iglesias parroquiales intramuros, que son San Andrés, San Esteban, San Pedro de los Picos, San Quirce, San Nicolás, la Santísima Trinidad, San Miguel, San Facundo, San Román, San Martín, San Sebastián, San Pablo, San Juan y San Bartolomé17 (Ruiz, 1982, I: 36). Estas iglesias se emplazan a una distancia similar entre ellas y "alrededor de todas estas parroquias se dispondría un caserío que constituiría las collaciones en que se asentarían estos repobladores" (Lojendio 1992: 224), lo que nos permite hacernos una idea de la posible extensión urbana de la Repoblación. Si incluimos los edificios de arquitectura civil ${ }^{18}$ que conservan partes y vestigios cuya cronología se puede situar en las mismas fechas, obtenemos más datos sobre la extensión y

${ }^{16}$ El barrio de las Canonjías era donde se alojaban los canónigos del Cabildo catedralicio, estaba aislado de la ciudad por tres puertas que se cerraban al anochecer. El solar fue cedido por el Concejo al Cabildo, según escrito fechado en 1120 (Ruiz, 1982, I: 31). No debemos olvidar que la antigua catedral románica se situaba delante del Alcázar, en la actual plaza de la Reina Victoria Eugenia, en una disposición muy similar a la que ambos edificios presentan en la ciudad de Zamora. ${ }^{17}$ La desaparecida iglesia de San Bartolomé estuvo situada en la esquina de la calle que desciende de San Nicolás al paseo del Obispo, la de San Facundo en la plaza de su nombre, San Pablo en la plaza del Conde Cheste, y San Román en la actual plaza del conde Alpuente. La primera parroquia que se cita en la documentación histórica es la de San Martín en 1103, en 1117 San Miguel y en 1120 San Andrés. Para un estudio pormenorizado de cada una de estas iglesias pueden consultarse Ruiz Hernando (2008) y García Guinea (2007).

18 Pertenecientes al siglo XII-XIII: Casa de Argila, Palacio Mansilla, Casa de los Lama, Torre de Hércules, Casa de los Condes de Chinchón, Casa de los Picos, Casa de los Cáceres, Casa de los Rueda, Casa no5 de la calle José Canalejas. Ya datado en el XIV, el Torreón de Lozoya (Ruiz, 2005: 81-98). Respecto a la arquitectura civil de Segovia existentes en los siglos XII al XIV ver el mismo autor, (Ruiz, 2007: 124-201), que aunque estudia los edificios de manera menos exhaustiva, recoge más ejemplares que no se mencionan en la publicación de 2005. 
alineaciones, que se mantienen, de ese caserío que conformaría la trama urbana. Las alineaciones definidas por estos edificios, especialmente los no exentos, nos confirman que el trazado de las calles sobre las que se ubican no se ha alterado desde la Edad Media, son por lo tanto una fuente de información fundamental para confirmar la existencia y las alineaciones (salvo modificaciones posteriores) de las calles actuales.

Por último, todo este conjunto urbano se encuentra encerrado dentro de una muralla, que se construye también en este momento, aunque como ya hemos indicado, consideramos que conserva amplios sectores de murallas previas (Martín, 2015).

Si sobre el plano representamos todos los edificios románicos que se conservan (Ruiz, 1982: 77-81) incluyendo todos los que presentan restos constructivos significativos o están documentados que pertenecen a los siglos XII y XIII, observamos que curiosamente se disponen de forma mayoritaria en una franja que discurre desde la puerta de San Juan hasta la iglesia de San Esteban, donde se continúa con el barrio de las Canonjías (ver figura 1).

¿Por qué no hay ninguna iglesia ni edificio de los datados cercanos a la Repoblación a lo largo del eje principal de la ciudad actual que discurre a lo largo de la calle Real hasta la calle Marques del Arco, salvo la iglesia de San Martín, y la desaparecida de San Miguel? De la iglesia de San Miguel sabemos poco más que estaba construida sobre una ermita previa ${ }^{19}$ y de la de San Martín ya hemos visto que aparentemente se trata de una iglesia que enmascara a otra anterior. En ambos casos, las nuevas iglesias se edifican, al menos parcialmente, sobre edificios preexistentes, pero todas las demás se sitúan en la zona norte de la ciudad.

Evidentemente la nueva población se asentaría en torno a esas recientes iglesias que se construirían como centro, al menos religioso, de las collaciones donde se emplazarían los foráneos. ¿Por qué esa asimetría en la Repoblación?

\footnotetext{
${ }^{19}$ La iglesia románica de San Miguel no existe en la actualidad y de ella se conocen escasos datos gracias a una intervención arqueológica en la que se hallaron el arranque de dos pilas de apoyo, que se datan en el XIII. Estaría situada en la actual Plaza Mayor frente a la calle Infanta Isabel (Barahona, 1997).
} 


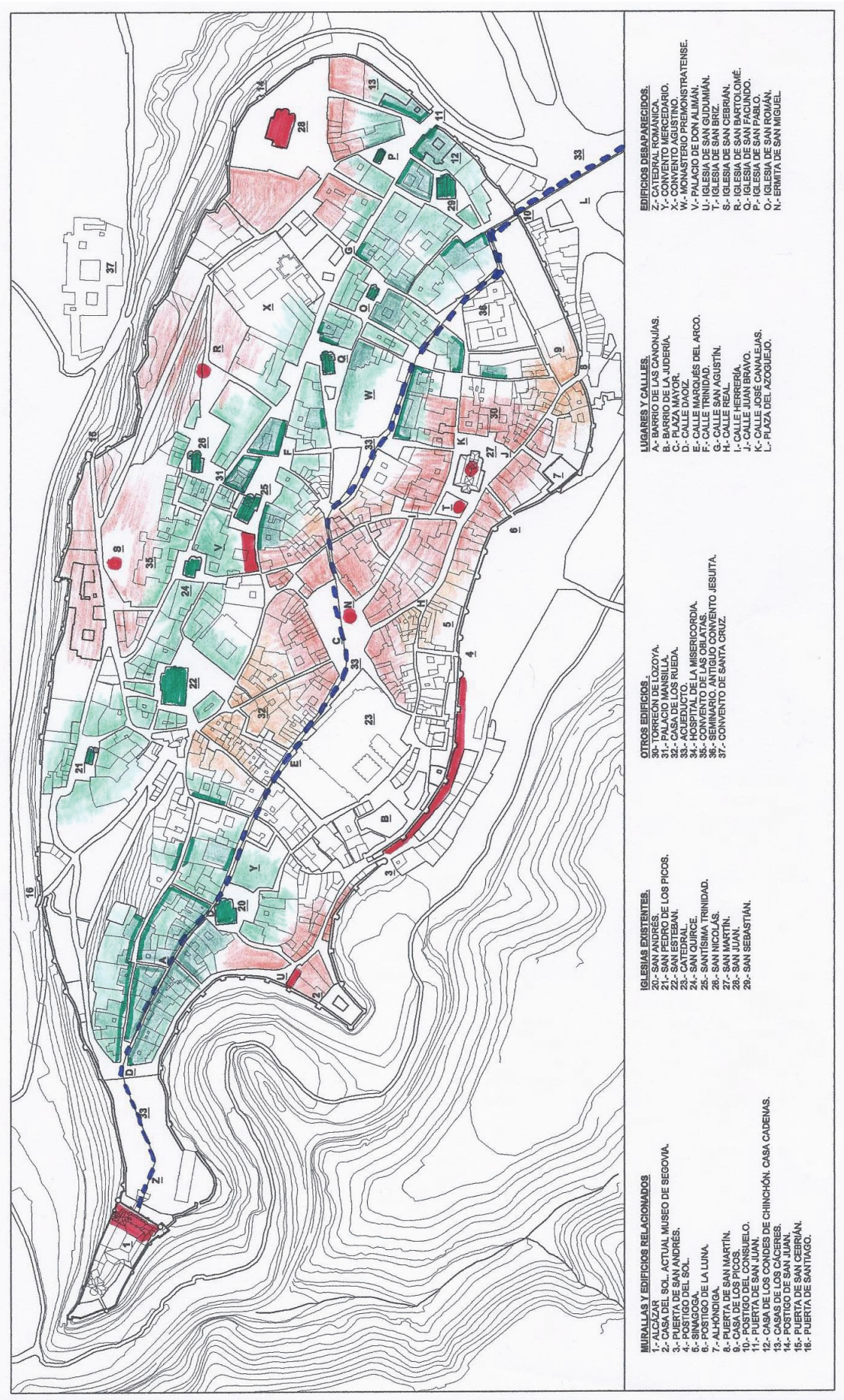

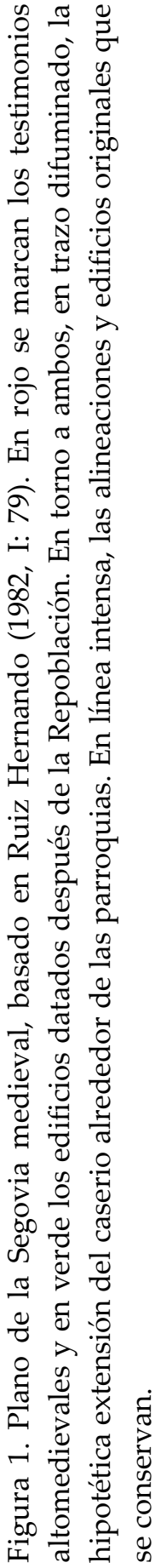


Ni la orografía ni la climatología explican este hecho. Las pendientes son similares en ambos sectores de la ciudad, a excepción de la parte más septentrional ya junto a la muralla donde las laderas comienzan a ser más empinadas. Respecto a la climatología, el razonamiento es mucho más evidente. ¿Por qué construir hacia la ladera norte, en vez de emplazarse en la ladera sur, mucho más soleada en el frío invierno segoviano? El abastecimiento de agua de estos nuevos barrios tampoco justificaría la elección, dado que desde el trazado actual del acueducto subterráneo, por la cresta orográfica, abastece igualmente a izquierda que a derecha, ya que ambos lados están a una cota inferior.

Nuestra hipótesis es que esa parte de la ciudad, a lo largo de la actual calle Real, ya se hallaba construida y habitada antes de la Repoblación de Alfonso VI. La "Repoblación" creemos que consistió más bien, especialmente en sus estadios iniciales, en una reorganización administrativa más que en un aporte de numerosa población nueva (Gautier, 1989: 50) ${ }^{20}$. El germen de la actual ciudad de Segovia, no se constituye con la Repoblación, sino que existía antes. Los nuevos pobladores vienen a completar un asentamiento preexistente, posiblemente muy poco poblado, de carácter más rural que urbano y sobre el que previamente no existía un control administrativo real, lo que explicaría la falta de documentación histórica previa. La rapidez con que se realiza el proceso de construcción de la ciudad tras la repoblación se deba probablemente a las importantes preexistencias que había anteriores a esta Repoblación (Benito, 2000: 191)

El primer barrio que se menciona en la documentación histórica es el barrio de San Martín en el año 1103 (Represa, 1949: 304), (García Guinea, 2007: 1435), por lo que se considera el barrio ya conformado en esa fecha, dato con el que se argumenta la rapidez de la Repoblación. San Andrés y San Miguel aparecen citadas en 1116 y 1117, poco después de la repoblación y en 1125

\footnotetext{
${ }^{20}$ De este modo, lo que se produce tras la invasión musulmana es realmente un proceso de desarticulación administrativa, unido a una importante debilidad demográfica, por lo que no existe un control político efectivo sobre dichos territorios y por lo tanto no existen referencias en los documentos oficiales a dichos territorios y sus ciudades. El vacío es más documental que poblacional. Esto explica que en numerosas villas se produzca una "repoblación" real mucho anterior a la documentalmente demostrable (Gautier, 1989: 50). Empleando la expresión de Monsalvo Antón, "Desierto administrativo" o "Vacío administrativo y tierra de nadie" (Monsalvo, 2010: 26, 50).
} 
San Andrés se menciona como postigo, aun no como puerta (Ruiz, 1973: 54). Obviamente para dar estos nombres a los barrios ya deberían existir las correspondientes iglesias parroquiales con dicha advocación.

Según nuestra hipótesis, lo temprano de la fecha está motivado, simplemente, porque dichos barrios ya existían con antelación, en torno a las posibles iglesias y ermitas previas sobre las que se edifican posteriormente las románicas. Mientras, todo el barrio de las Canonjías, claramente documentado que se construye tras la Repoblación, se asienta sobre un espacio que se denominaba Almuzara, cuya etimología, como hemos visto, parece sugerir que fuese un espacio libre o con escasas construcciones, por el que discurre el acueducto subterráneo. Aun así, creemos que la Repoblación no fue tan numerosa, ni tan rápida ${ }^{21}$ y la ciudad, lejos de presentar un continuo edificado, mantendría importantes vacios, con huertas, vides, como nos la describe Garci Ruiz de Castro (1551: 5), de forma que estos barrios parecerían más bien aldeas, en torno a las iglesias (Ruiz, 1973: 54). Toda la ciudad tendría una imagen bastante rural.

\section{El análisis de la estructura urbana.}

Así pues, nos encontramos ante dos momentos del desarrollo urbano de Segovia cuyo punto de inflexión es la ya mencionada Repoblación. La existencia de una ciudad previa, sin duda debe presentar unas características compositivas distintas de las de la nueva ciudad de Repoblación. "El estudio de la ciudad desde el aspecto del urbanismo histórico es una fuente de incalculable valor, que ofrece a los urbanistas una información que no se puede obtener de los textos históricos" (Arizaga, 2002: 69). Al igual que con una lectura constructiva de los muros de un edificio es posible entender su proceso histórico, la lectura de la trama urbana también permite identificar las cicatrices y suturas que el paso del tiempo y el palimpsesto cultural de la distintas generaciones van dejando, a modo de huella, impresa en la forma urbana.

\footnotetext{
${ }^{21}$ Prueba de que la Repoblación no es tan inmediata, es el hecho de que se otorguen varios privilegios y franquicias reales a lo largo de los años para que acudan vecinos y se asienten en el interior del recinto amurallado (Ruiz, 1973: 74). Por otra parte, el barrio de las Canonjías contaba con tan solo doce monjes en 1133. En 1285, 200 años después de la Repoblación, había setenta personas, entre canónigos, racioneros, medio racioneros, etc. (Ruiz, 1973: 74-75).
} 
Son muy contados los casos en que podemos conocer de manera inequívoca las alineaciones históricas de los edificios y calles. Así, el entorno de la Plaza Mayor ${ }^{22}$, el de la Catedral ${ }^{23}$ y buena parte de la Judería son fruto de importantes transformaciones producidas varios siglos después de nuestra época de estudio, que han alterado por completo la trama viaria, la forma de las manzanas, las alineaciones exteriores y el parcelario, no pudiendo obtenerse ningún tipo de información para nuestros objetivos. En torno a la iglesia de San Juan de los Caballeros ha desaparecido la trama urbana por completo, al igual que en los importantes vacíos edificatorios de la ladera norte, donde a partir de la Baja Edad Media se implantaron diversas instituciones como el convento de los Agustinos, el de las Oblatas o el Hospital de la Misericordia.

\footnotetext{
${ }^{22}$ El hundimiento de la iglesia románica de San Miguel en 1532, posibilita la creación de un amplio espacio urbano en la plaza del mismo nombre, en la que se desarrollaba un mercado semanal desde 1448 y que ya venía denominándose Plaza Mayor desde 1461. En 1536 se reconstruye la iglesia de San Miguel en su nuevo emplazamiento. En 1611 se presentan las trazas por Pedro de Brizuela para la reordenación de la Plaza Mayor, comenzando por el alzado del edificio del Ayuntamiento. En 1623 Brizuela presenta unas trazas para reordenar toda la plaza y en 1630 un proyecto para el alzado del actual teatro y las casas adosadas delante de la iglesia de San Miguel, que no llega a ejecutarse. La alineación de edificios de la calle de San Frutos frente a la catedral se realiza sobre un trazado posterior al diseño de la Plaza Mayor, algo que se evidencia por el diseño soportalado de su planta baja, que se empareja perfectamente con el del resto de la plaza, si bien en esta calle se ha perdido el soportal abierto, aunque se conserva la estructura de pilares de granito embebidos en las fachadas de los inmuebles. Su traza es posterior al siglo XVI.

${ }^{23}$ Tras la Guerra de las Comunidades, la Catedral románica situada en los actuales jardines frente al Alcázar queda muy dañada al haberse encastillado en ella las tropas comuneras y el Rey Carlos I manda construir la nueva Catedral en otro emplazamiento. Tras la expulsión de los judíos en 1492 la Judería se ha convertido en una zona de la ciudad muy despoblada por lo que se implanta allí el nuevo edificio. En 1568 la Catedral ya ha llegado al crucero, considerándose finalizadas las naves. En 1587 se despeja de casas el enlosado a los pies de las naves. Obviamente, todas las calles que rodean a la Catedral, se trazan posteriormente a su construcción, ciñéndose su trazado al perímetro de la iglesia. Por lo que los edificios serán todos posteriores a la Edad Media. Posibles preexistencias se denotan en el edificio de la esquina de Doctor Castelo, $\mathrm{n}^{\mathrm{o}}$ 2, en que se aprecia que la fachada en planta baja se ha adelantado respecto a una esquina previa, marcada por los sillares esquineros. Por otra parte el edificio de la calle Judería Vieja $n^{0} 2$ evidencia una parcela en origen dispuesta entre medianeras, indiferente a la actual situación en esquina, lo que nos hace sospechar que ese edificio es anterior a la apertura de la calle San Frutos, y que la demolición del edificio (o edificios) que continuaban el trazado de la actual calle Judería Vieja se adosaban a él, dando continuidad a la manzana.
} 
A pesar de estas grandes deficiencias de información y los siglos transcurridos, el análisis de la estructura urbana aún nos permite atisbar la existencia de dos tramas urbanas diferenciadas y creemos que existen suficientes fragmentos urbanos donde obtener unas características que nos permiten diferenciar estos dos tipos de urbanismo, que podríamos definir como el de la Segovia altomedieval y el de la Segovia de la Repoblación oficial. El primero lo reconocemos, alterado y discontinuo por transformaciones posteriores, en forma de franja desde la antigua Puerta de San Martín a lo largo de las calles Real, Juan Bravo y Herrería hasta la Plaza Mayor y continúa al otro lado de ésta por la calle Escuderos hasta el encuentro con la calle Desamparados (lo llamaremos zona 1, a partir de ahora). El segundo tipo lo identificamos en el área comprendida entre las calles San Agustín y Trinidad y en el barrio de las Canonjías (zona 2). Veamos las características que nos permiten establecer esta distinción.

\subsection{El trazado de las calles y las plazas.}

En la trama urbana del recinto amurallado de Segovia pueden distinguirse dos tipos de calles, unas que calificamos principales, que se caracterizan por trazados más largos y que generalmente enlazan dos puntos distantes de la ciudad, y las secundarias, cuya función es enlazar entre sí distintos puntos de las calles principales, organizando una comunicación transversal entre ellas, lotificando el espacio construido en manzanas.

Las calles principales presentan unas características similares en ambas zonas, si bien en la zona 2 su trazado presenta con más claridad una trayectoria lineal, mientras en la zona 1, su trazado es más errático, menos directo y rectilíneo. Las diferencias se hacen más evidentes al comparar las calles secundarias. En la zona 2 se aprecian claramente una red de calles de segundo orden, de trazado recto, claramente premeditado, que enlaza transversalmente las calles principales, con alineación decididamente ortogonal, constituyendo unas manzanas de trazado bastante regular. Estas calles secundarias garantizan un alto grado de permeabilidad transversal del espacio público, con clara tendencia a la ortogonal respecto a la vía principal, aunque en algunas manzanas, a pesar de su regularidad, pervive el sistema de interior de callejones, heredado de los corrales. Sin embargo en la zona 1, no existen estas calles secundarias, las manzanas adquieren formas organicistas, irregulares y la trama urbana resulta poco 
permeable en la dirección transversal, ya que estas conexiones secundarias se realizan por el interior de la manzana a través de callejones semiprivados, con una configuración y funcionamiento basado en los corrales (ver figura 2).

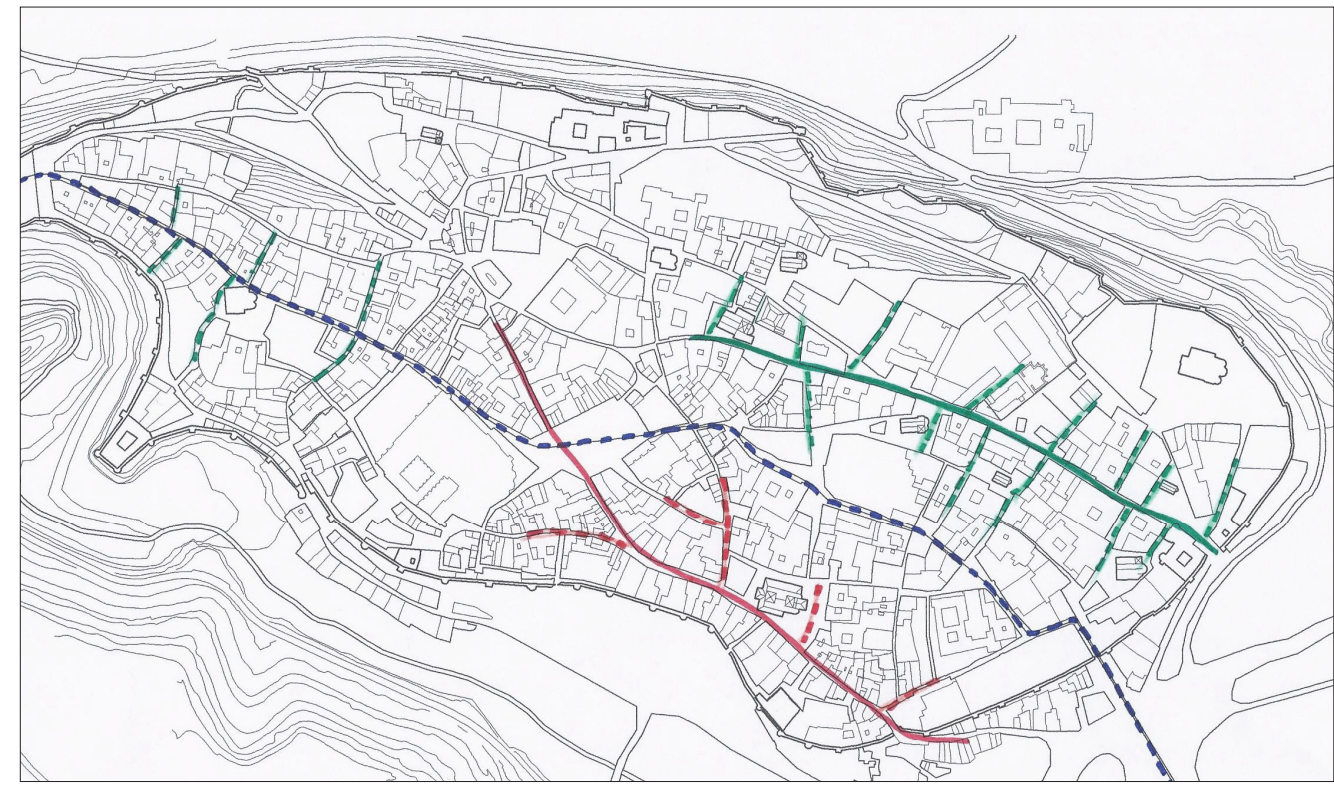

Figura 2. Trazado de calles. En rojo calles pertenecientes al urbanismo del tipo 1 y verde las correspondientes al tipo 2. Nótese como en el segundo caso hay una red de calles secundarias que articulan la comunicación transversal, inexistente en el tipo 1. Fuente: elaboración propia.

Así en ambas zonas, las calles principales son bastante rectas, pero manifiestan un cierto serpenteo que evidencia su trazado espontáneo, resultado del paso continuado, un tanto aleatorio, como el de los senderos que se generan atravesando un solar urbano o en el campo. Estos se crean casualmente por los transeúntes, su trazado se materializa lentamente, de forma inconsciente, por el reiterado uso a lo largo de los años. Generan una trama acomodada a las necesidades sociales. Manifiestan un trazado basado en el discurrir de un camino, cuyo concepto es enlazar dos puntos por el recorrido más corto, o más cómodo si tenemos en cuenta la topografía.

Por el contrario, en la zona 2, la malla urbana tiende claramente a la retícula ortogonal, no toda ella unitaria, sino por sectores. Los ejes principales presentan un trazado ligeramente serpenteante, que ya hemos comentado en la 
zona 1, como si en un origen fuesen caminos. Estructuradas a ambos lados de estos ejes principales, las calles secundarias se trazan intencionadamente, de forma perpendicular y casi totalmente rectas. En algunos casos, la presencia de escaleras permite mantener esa regularidad a costa de una pendiente poco confortable en las calles secundarias. En los casos de mayor pendiente, especialmente en la ladera que desciende hacia la muralla norte, la retícula se deforma buscando lo que serían las diagonales de la retícula para reducir las pendientes de las calles principales configuradoras del trazado, mientras las transversales y secundarias, se mantienen en su dirección ortogonal a estas principales, recurriendo a la solución mediante escaleras, o se desvían ligeramente pero mantienen un ángulo similar al de 90 grados.

Si observamos el trazado de las calles y la forma en que estas se encuentran se percibe una diferencia entre ambas zonas. En la zona 1, las calles se encuentran principalmente en forma de $Y$, confluyendo en ángulo agudo y sin generar nunca un cruce de cuatro esquinas enfrentadas y mucho menos una plaza, a lo sumo un pequeño ensanchamiento al bifurcarse los trazados, que no presenta ángulos rectos, sino más bien perímetros poligonales de numerosos lados que suavizan sus aristas. En algunos casos apreciamos un encuentro en una forma cercana a la $\mathrm{T}$, pero no es ortogonal. Las orientaciones de las calles no muestran una orientación preferente. En la zona 2, las calles tienen unas direcciones predominantes y los encuentros de las calles tienden intencionadamente a la perpendicularidad, incluso algunas calles, giran ligeramente en su trazado para acometer con un ángulo más cercano a los $90^{\circ}$ a la calle principal. Son frecuentes los cruces con cuatro esquinas enfrentadas, dos calles que se encuentran y ambas continúan, e incluso la formación de plazas en dichos cruces, en las que sus lados se encuentran ortogonalmente (ver figura 3).

Esas plazas no son espacios públicos con el concepto actual, no son grandes plazas, sino son desahogos de una trama urbana muy constreñida, casi nos parecen sencillos ensanches de las calles que aparecen junto a las iglesias, ante las puertas de las murallas y en los lugares de mayor tránsito o de reunión de vecinos. Sin embargo, a pesar de su reducido tamaño, su diseño y su disposición evidencian intencionalidad y regularidad, tendiendo a formas poligonales de ángulos rectos, como vemos en los casos de San Pedro de los Picos, la Santísima Trinidad, San Nicolás, San Román por citar los casos más evidentes, ya que han llegado a nuestros días las alineaciones originales del caserio circundante. 


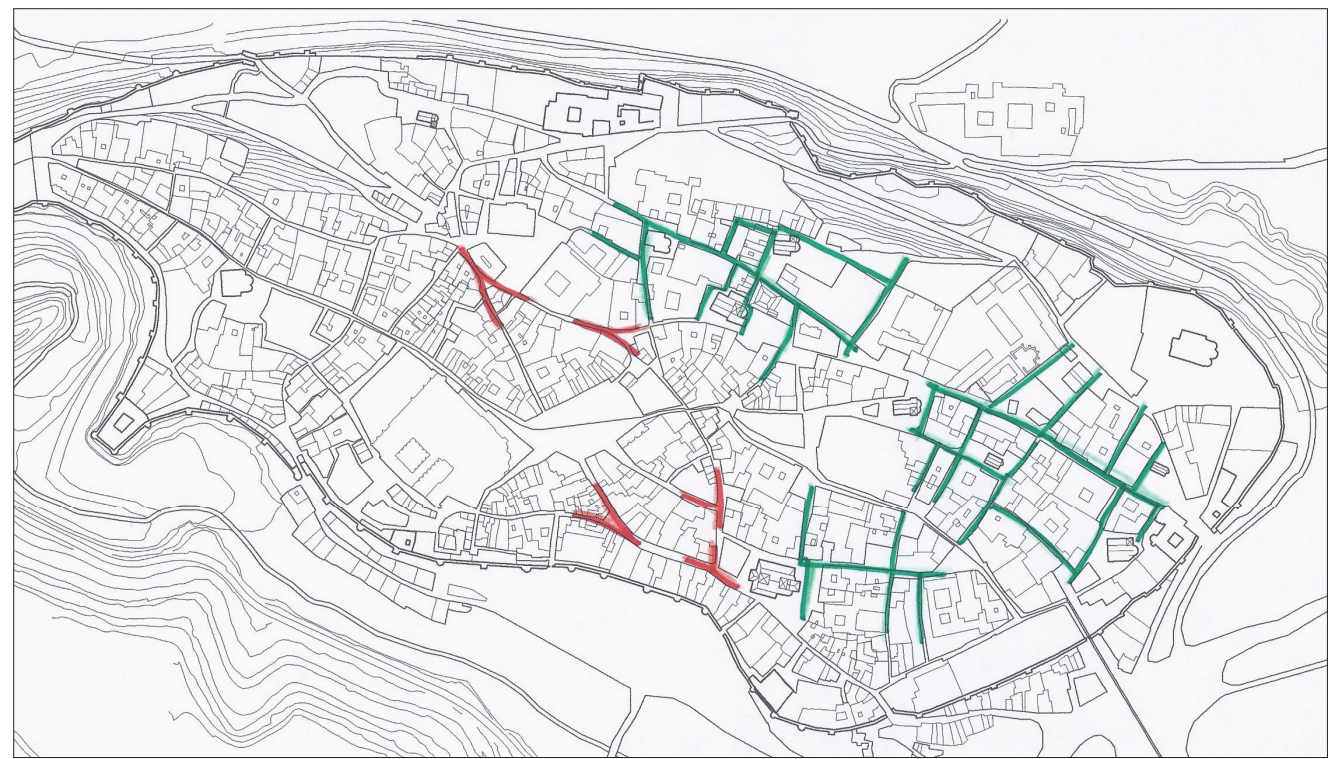

Fig. 3. Tipos de cruces de calles. En rojo se representan los cruces que caracterizan las calles de la zona 1. En verde los de la zona 2. Mientras en el primer caso los encuentros son en $Y$, sin una orientación clara, en el segundo tipo la búsqueda de calles ortogonales a las calles principales es evidente. La retícula se va deformando al acercarse a la zona 1 perdiéndose en un área de transición que resuelve el encuentro entre ambas tramas urbanas. Fuente: elaboración propia.

Sin embargo, en la zona 1 no existe ninguna plaza que no sea fruto de transformaciones posteriores ${ }^{24}$. Tan solo encontramos pequeños ensanches de la trama viaria motivados por el cruce en $\mathrm{Y}$ de las calles. Sus dimensiones son mínimas y su forma tiende a ser triangular frente a la forma rectangular que observamos en la zona 2.

\subsection{La morfología de las manzanas y la tipologia de parcelas.}

Las mismas características de improvisación, en un caso, y regularidad en el diseño en el otro, que apreciamos en el recorrido de las calles de cada una de las zonas, se observan en el trazado de las manzanas (ver figura 4). En la zona 1 esta aleatoriedad en la trama viaria supone que las manzanas en vez de tender a la regularidad del paralelepípedo adoptan formas ameboides,

\footnotetext{
${ }^{24}$ No debemos olvidar que algunas de las actuales plazas se generan por reformas de alineaciones o el derribo de iglesias y conventos a finales del siglo XIX, como señala Jürgens (1992: 111).
} 
organicistas, de perímetros completamente casuales, con trazas irregulares por lo que sus lados tienen escasos tramos rectos, denotando que no existe ningún criterio previo de trazado, son producto de una yuxtaposición de parcelas a lo largo de una calle o camino. Las esquinas en ángulo recto son excepcionales. En el interior de estas manzanas se organiza una red de callejones y patios, secuencias de pequeños espacios semiprivados y privados que remiten a la estructura de corrales urbanos.

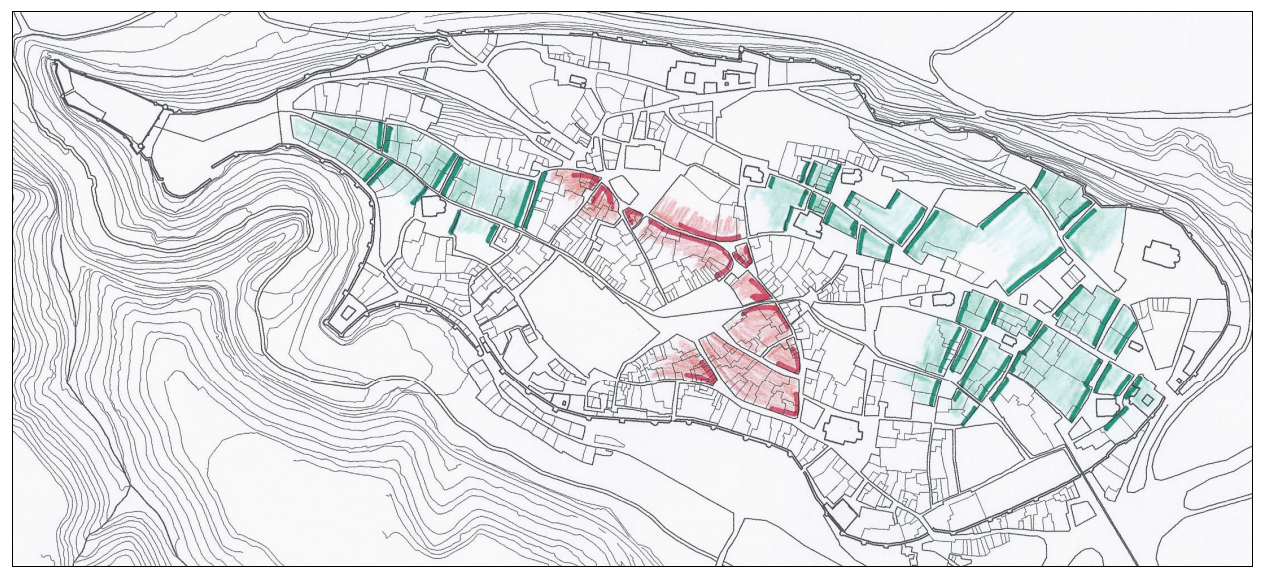

Figura 4. Morfología de las manzanas. En rojo se grafían las manzanas pertenecientes al tipo 1 y en verde las del tipo 2. Mientras las primeras son manzanas de forma irregular y con abundantes esquinas en ángulo agudo, el segundo tipo se caracteriza por la mayor regularidad, con tendencia al paralelepípedo rectangular con esquinas en ángulo recto. El predominio de las direcciones definidas por las calles principales y sus perpendiculares es patente. Fuente: elaboración propia.

Sin embargo en la zona 2, las manzanas adquieren formas más regulares, tendiendo al rectángulo, sus lados son más rectos y sus esquinas son, en la mayoría de los casos, ángulos rectos resultado del encuentro de dos calles ortogonales. El predominio de las direcciones definidas por las calles principales y sus perpendiculares es patente. Si bien "la manzana es la unidad mínima a partir de la cual puede efectuarse algún tipo de análisis acerca de la transformación de la ciudad" (Passini, 2011: 37) creemos que el parcelario también presenta algunos matices que pueden respaldar nuestra hipótesis.

Si observamos el parcelario de la zona 1 es claramente más denso que el de la zona 2. Las parcelas son más pequeñas, su forma no es tan regular y su dis- 
posición vuelve a evidenciar la espontaneidad y aleatoriedad que viene manifestando este urbanismo que hemos designado como previo a la Repoblación. Las parcelas y los edificios se van yuxtaponiendo unos a otros sin una lógica geométrica que lo organice salvo la calle, el camino. Se trata de una sucesión de parcelas alineadas a lo largo de una calle, en el que cada una se va adosando a la anterior sin ningún plan preconcebido. La aparición de calles transversales ocurre de forma espontánea, sin generar en el parcelario la singularidad que supone la esquina. Simplemente es como si se hubiese eliminado una de esas estrechas parcelas para permitir la conexión transversal, pero sin ninguna repercusión en el parcelario.

La escasez de fondo construible que presentan las parcelas en dirección perpendicular a esta calle secundaria, muestra a las claras que dicha calle no se ha considerado en ningún momento como fachada. En las parcelas en esquina de la zona 2, la proporción de las parcelas tiende más hacia el cuadrado, igualándose la dimensión del fondo y fachada hacia ambas calles, por lo que la tipología edificatoria que se puede implantar en dicha parcela cambia completamente respecto a la de las parcelas alargadas de poca fachada y mucho fondo. Incluso en algunos edificios que en la actualidad se conservan en estas circunstancias, dicha fachada se mantiene prácticamente sin apertura de ventanas, ni puertas de acceso. Esto es, la distribución interior del inmueble está tan condicionada por la forma y dimensión de la parcela, que no se ha alterado a lo largo de varios siglos. Es una parcela dimensionada para situarse entre medianeras, no en esquina. Aunque presente fachada a dos calles, en esquina, sus dimensiones no permiten distribuir la vivienda de otra forma, no se puede aprovechar esa segunda fachada.

Se trata de parcelas con una eminente proporción longitudinal con predominio del fondo sobre el ancho de fachada (Passini, 1984: 66) en claro contraste con la forma y las proporciones que poseen las parcelas de la zona 2, constituidas mediante lotificaciones de parcelas regulares de mayores dimensiones, especialmente en fachada, y proporciones más cuadradas. La parcela de la repoblación tiende a la forma rectangular, debido a la necesidad de adaptarse a una calle y una manzana preestablecidas en las que predominan los trazados rectos y ortogonales. Presenta un fondo mucho más proporcionado al frente de fachada, de forma que permite una distribución interior en torno a un patio, generalmente centrado, y en el caso de edificios en esquina con 
apertura de ventanas a ambas calles, algo que no ocurre en la tipología de parcela que consideramos más primitiva de la zona 1.

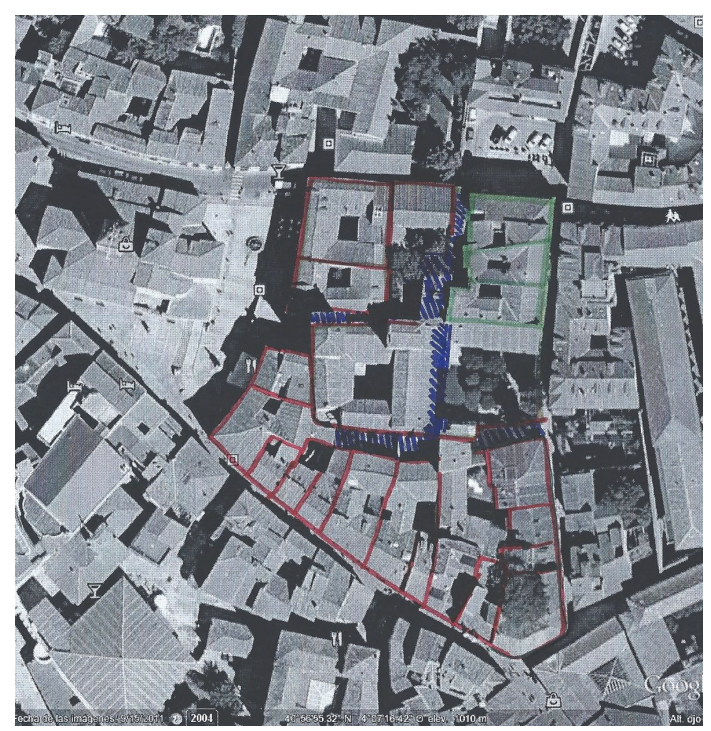

Figura 5. La transición entre ambas tramas urbanas. Una manzana en que conviven ambos modelos. La mitad superior de la manzana es claramente regular, conforme a las características de la zona 2. La mitad inferior de la manzana, por contra, se configura de acuerdo a los parámetros de calles, esquinas, manzanas, parcelas y edificaciones definidas para la zona 1. Foto SIGPAC.

En la manzana frente al ábside de la iglesia de San Martín, creemos que aún se aprecia con claridad el encuentro de las dos tramas urbanas y distinguimos los dos tipos de parcelas y de configuración urbana. Superponemos sobre la foto aérea, el parcelario de $1752^{25}$ y observamos como en la parte superior de la manzana, las parcelas son de trazado más regular, de mayores dimensiones y ordenadas en base a una retícula imaginaria cuyas direcciones las define la calle José Canalejas y la dirección perpendicular al eje de ésta. Estas dimensiones permiten un patio central en torno al cual se organiza el edificio. Por el contrario, en el lado sur de la manzana, las parcelas presentan una dimensión sensiblemente inferior, dispuestas claramente a lo largo del trazado de la calle Juan Bravo, mediante la yuxtaposición, con los condicionantes del trazado de la calle y la medianera de la parcela adyacente. Los patios están situados al fondo de la parcela, dado que su escasa anchura no permite otra disposición. Hay que aclarar que la casa Eraso, situada en el medio de la manzana sin adaptarse a ninguna de las

${ }^{25}$ Desde 1752 se han producido numerosas agrupaciones de parcelas, lo que posibilita edificios más acordes con los estándares de vida de los siglos posteriores, especialmente en los siglos XIX y XX. Así la diferencia entre los dos tipos de parcelas existentes se acentúa aún más al comparar con el parcelario del catastro de Ensenada (Nos basamos en Ruiz Hernando, 1982). 
dos alineaciones que comentamos, se construye en el siglo XVI, adosándose al Torreón de Lozoya, preexistencia de carácter militar, que se conserva en el frontal del edificio, por claros motivos simbólicos, de forma que éste constituye el frente del edificio ${ }^{26}$, lo que condiciona el emplazamiento del resto de la vivienda en el interior de la manzana, ajena a la estructura urbana que estamos comentando. Aun así, el trazado de sus patios y crujías se rige por la retícula de la zona 2. La mitad superior de la manzana es claramente regular, de esquinas a $90^{\circ}$ conforme a la disposición marcada por las calles que la flanquean de trazado perpendicular. Cumple todas las características dadas para la zona 2. La mitad inferior de la manzana, por contra, se configura de acuerdo a los parámetros de calles, esquinas, manzanas, parcelas y edificaciones definidas para la zona 1.

\section{La ciudad de la Repoblación.}

Encontramos dos tipos de urbanismo claramente diferenciados, uno espontáneo y otro planificado. Uno primitivo, de crecimiento no planificado, y otro más evolucionado. Entre ambos, una zona de charnela absorbe las irregularidades y resuelve el encuentro entre ambas tramas urbanas.

En la zona 1, confirmamos la pervivencia de un urbanismo más primitivo, caracterizado por una falta de planificación previa del espacio público. Esta parte de la ciudad se organiza a lo largo de calles-camino ${ }^{27}$, que enlazan las puertas de la muralla entre sí (Gautier, 1989: 311) y con los centros políticos, religiosos o económicos de la ciudad. Es la zona que consideramos el germen de la ciudad actual, y que llamamos la ciudad previa a la Repoblación oficial.

El elemento principal en este urbanismo es la calle, la cual surge inconscientemente por el reiterado paso de los transeúntes a lo largo del tiempo, de forma espontánea, sin planificación como se ha indicado. Los demás elementos, parcela, manzana, esquina, surgen como respuesta, ajustándose a una forma ya establecida por la calle principal y se denota la misma espontaneidad en la creación de calles secundarias o transversales, callejones y adarves. Las parcelas son una mera yuxtaposición a lo largo de un camino y la apari-

\footnotetext{
${ }^{26}$ Agradezco esta información a Ana Escobar González, cuya tesis aún inédita estudia las casas torre segovianas.

27 Para profundizar en el estudio del urbanismo medieval véase (Torres Balbás, 1968 y 1985); (Alomar, 1980); (Passini, 1984 y 2001); (Gautier, 1989); (Sainz, 1990); (Benito, 2000); (Gómez, 2011).
} 
ción de una calle transversal genera la manzana, también sin planificación previa. Así este viario presenta una menor permeabilidad transversal y menor regularidad de trazado, aspectos que no se justifican por la orografía, muy similar en toda la parte central de la ciudad amurallada. Estos detalles nos hacen pensar en un urbanismo arcaico, ruralizante, si quiere emplearse la expresión de Crespo Redondo (2007: 238).

Las ciudades de trazado irregular denotan un crecimiento espontáneo, no hay voluntad repobladora, ni un proyecto deliberado (Gautier, 1989: 17).

En la zona 2, la que consideramos la ciudad de la Repoblación, sobre una mínima red de caminos preexistentes que enlazan los principales puntos de la ciudad, se ejecuta un trazado planificado previamente en el que las calles tienden a la retícula ortogonal y en la que se configura la creación de pequeñas plazas en algunos cruces o en los entornos de los edificios singulares. Un trazado geométrico en el que predomina el encuentro ortogonal de las calles, en cruz, que empieza a ser frecuente a partir del siglo XIII y conserva su vigencia hasta entroncar con los modelos renacentistas (Montero Vallejo, 1996: 217). Este urbanismo más evolucionado, requiere inevitablemente de una autoridad política, un poder que planifica la ciudad previamente y tiene capacidad para imponer y hacer cumplir ese plan preestablecido.

La repoblación oficial supone un reparto organizado de las parcelas en el que no se deja lugar a la iniciativa privada, tal y como queda constatado por la documentación histórica en que se hace referencia a la repartición del suelo (Gautier, 1989: 35).

La densidad del parcelario es sensiblemente menor en la nueva ciudad, con parcelas más grandes y dispuestas conforme a una manzana predefinida. No se trata de una sucesión de parcelas alineadas a lo largo de una calle, como hemos visto anteriormente sino de un trazado de calles y manzanas, consciente de que va a subdividirse en unidades menores, las parcelas, tendentes a la regularidad para un mejor aprovechamiento edificatorio. El elemento principal de este urbanismo es la parcela y en base a ésta se diseñan previamente las calles y las manzanas, siendo consciente de que éstas últimas van a subdividirse en unidades más pequeñas que tienen que seguir siendo funcionales.

El crecimiento de las ciudades fundadas o restauradas en el XI y XII estuvo en cierto modo guiado o controlado. Pero las aglomeraciones de plano verdaderamente regular, trazado antes del establecimiento de los "populatores", no parecen anteriores al siglo XIII (Gautier, 1989: 313). 


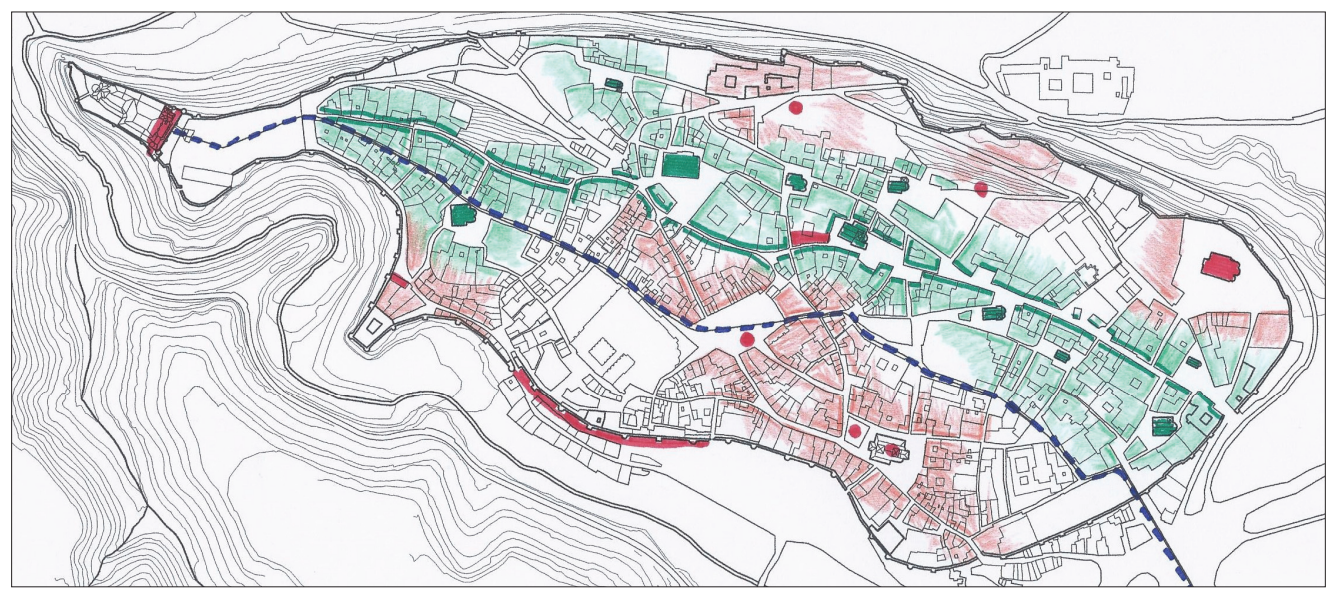

Figura 6. La ciudad de la Repoblación. En rojo se marcan los testimonios altomedievales y en verde los edificios datados después de la Repoblación. En torno a ambos, se figura un caserío hipotético en trazo difuminado. En línea intensa, las alineaciones y edificios originales que se conservan. Se evidencia el trazado unitario de todo el eje, "La Rúa" que desde la Puerta de San Juan pasa por delante del Palacio de Don Alimán y conecta con el nuevo viario del barrio de las Canonjías, hasta el Alcázar. Fuente: elaboración propia.

El elemento principal en este urbanismo, ya no es la calle, ahora es la parcela. Calles y manzanas se trazan pensando en la geometría. Como atinadamente titulase Torres Balbás (1968), se trata de un nuevo ideal urbano. Este nuevo concepto urbano a partir del siglo XIII se recoge en las ordenanzas que empiezan a hablar de "enderezar las calles" (Montero, 1996: 286). Esta malla viaria presenta simultáneamente un mayor número de calles transversales que permite una mejor conexión en dirección transversal. Se trata de una red viaria planificada, con voluntad de generar ciudad, no exclusivamente de comunicar dos puntos.

Todo el conjunto de la ciudad de la Repoblación se estructura supeditado a un nuevo eje urbano a lo largo del que se disponen todas las parroquias y las nuevas collaciones, trazado de forma premeditada, organizando el espacio a ambos lados y enlazando la Puerta de San Juan con el nuevo vial que se plantea en el barrio de los canónigos (Remolina, 2006: 411). Resulta significativo que este eje, que pasa por delante del antiguo Palacio de Don Alimán, en la Edad Media recibía el nombre de "la Rúa" (Ruiz, 1982, I: 39), denotando la importancia que la sociedad medieval segoviana otorgaba a esa calle, singularidad que la toponimia nos ha conservado. 
La constatación de estos dos modelos de urbanismo, nos plantea nuevas preguntas que guiarán nuestras futuras líneas de investigación. ¿Se trata de dos fases de la Repoblación o se trata de la Repoblación oficial que se asienta sobre una ciudad previa, de forma que Segovia es una ciudad mudéjar, en el sentido que Torres Balbás dió a dicho termino? Son las preguntas que nos planteamos en la continuación de nuestra investigación.

\section{Bibliografía.}

AlONSO AvilA, Ángeles (1989). “La visigotización de la Provincia de Segovia". Estudios Segovianos, XXX, no 86: 250-286.

AlOMAR ESTEVE, Gabriel (1980). Teoría de la ciudad. Madrid: Instituto de Estudios de Administración Local.

ARIZAGA BOLUMBURU, Beatriz (2002). La imagen de la ciudad medieval: La recuperación del paisaje urbano. Santander: Universidad de Cantabria.

BARAHONA TEJEDOR, Pilar (1997). Excavaciones arqueológicas en la plaza mayor de Segovia. Informe inédito depositado en el Servicio Territorial de Cultura de Segovia. № expediente: SG. 08/97.

BARRIO MARTÍN, Joaquín (2010). “Las comunidades indígenas segovianas a la llegada de Roma" en Segovia romana II. Gentes y territorio. Santiago MARTíNEZ CABAllero, Jorge SANTIAGo PARDO y Alonso ZAMORA CANELladA (coords). 15-37. Segovia: Caja Segovia.

BENITO MARTíN, Félix (2000). La formación de la ciudad medieval. La red urbana en Castilla y León. Valladolid: Universidad de Valladolid.

BETRÁN ABADÍA, Ramón (1992). La forma de la ciudad. Las ciudades de Aragón en la Edad Media. Zaragoza: Colegio Oficial de arquitectos de Aragón.

COOPER, Edward (2014). La fortificación en España en los siglos XIII y XIV. Madrid: Marcial Pons Historia; Ministerio de Defensa.

CRESPO REDONDO, Jesús (2007). La evolución del espacio urbano de Burgos durante la Edad Media. Burgos: Dossoles.

Chaves MARTíN, Miguel Ángel (2006). Segovia. Guía de Arquitectura. Segovia: Colegio de Arquitectos.

CHUECA GoITIA, Fernando (1989). Historia de la arquitectura occidental. Tomo IV. Edad Media cristiana en España. Madrid: Dossat.

Cómez RAMOS, Rafael (2011). "El urbanismo alfonsi" en Alcanate, Revista de Estudios Alfonsíes. Vol VII: 43-101. Sevilla: Cátedra Alfonso X el Sabio. 
GómEZ DE SOMORROSTRO, Andrés (1820). El Acueducto y otras antigüedades de Segovia. Madrid: Miguel de Burgos.

García GuineA, Miguel Ángel y José María PÉREZ GonZÁlez. (Dir) (2007). Enciclopedia del Románico en Castilla y León. Segovia. Volumen III. Aguilar de Campoo: Fundación Santa María la Real.

GAUTIER DALCHÉ, Jean (1989). Historia urbana de León y Castilla en la Edad Media (siglos IX -XIII). Madrid: Siglo XXI.

GONZÁLEZ Y GONZÁLEZ, Julio (1974). "La Extremadura castellana al mediar el siglo XIII". Hispania. Revista Española de Historia. XXXIV. № 127: 265-424. Madrid: Instituto Jerónimo Zurita.

GROMA, 2011. Informe de intervención arqueológica previa a la reurbanización de la calle Daoiz en Segovia. Informe inédito depositado en el Servicio Territorial de Cultura de Segovia. № expediente: OT-339/2011-11.

GuTIÉRREZ GonZÁLEZ, José Avelino. 1999. “Génesis del urbanismo en la ciudad de León y su transformación en la Edad Media", en Fernando VALDÉS FERNÁNDEZ (coord.) Actas III Curso sobre la Península Ibérica y el Mediterráneo entre los siglos XI y XII. Codex Aquilarensis no 15: 43-90. Aguilar de Campoo: Fundación Santa María la Real; Centro de Estudios del Románico.

HEERS, Jacques (1978). El clan familiar en la Edad Media. Barcelona: Labor S.A.

HOZ ONRUBIA, Jaime de (2006). Castilla visigoda. El legado onomástico de los godos del sur del Duero. Madrid: Fundación Diego de Sagredo.

JÜRGENS, Oskar (1992). [1926] Ciudades españolas: su desarrollo y configuración urbanística. Madrid: Ministerio para las Administraciones Públicas.

LABRAdOR VIELBA, José Miguel y Clara MARTín GARCíA. 2014. Memoria final de la intervención arqueológica vinculada al proyecto de restauración de la muralla de Segovia y revalorización de su entorno entre la torre 59 y el jardín del alcázar. Informe inédito depositado en el Servicio Territorial de Cultura de Segovia. № expediente: OT-189/2013-11.

LoJENDIO, Luis Ma de (1992). Castilla/2. La España Románica. Madrid: Encuentro. LÓPEZ-AMBITE, Fernando y Yolanda BARrio ÁlvAREZ (1995). Excavaciones en la iglesia de la Santísima Trinidad. (Segovia). Valladolid.

MARQUÉS MARTÍN, Isabel (2009). “Segovia y su gestión arqueológica desde la perspectiva profesional", en Actas de las Jornadas Técnicas sobre Arqueología, Patrimonio Histórico y Urbanismo. 203-215. Grupo Ciudades Patrimonio de la Humanidad de España. 
MARTín BlanCO, Miguel Angel (2015). "Las murallas de Segovia en la Alta Edad Media. Una interpretación constructiva" en Cuadernos de Arquitectura y Fortificación, 1: 35-66. Madrid: La Ergástula.

MARTínez CABALlero, Santiago y Jorge SANTIAGO PARDO (2010). "La ciudad de Segovia y su territorio" en Segovia romana II. Gentes y territorio: pp. 143181. Segovia: Caja Segovia.

Martínez Caballero, Santiago (2012). El Acueducto de Segovia. De Trajano al siglo XXI. Segovia: Ayuntamiento de Segovia. RFSG: Segovia.

MARTínEZ DE PISÓN, Eduardo (1976). Segovia. Evolución de un paisaje urbano. Madrid: Colegio de Ingenieros de Caminos, Canales y Puertos.

MERINO DE CÁCERES, J.M. (2005). “La torre de la iglesia de San Millán de Segovia y su construcción", en Santiago HuERTA (Ed.), Actas IV Congreso Nacional de Historia de la Construcción. Vol II: 771-779. Madrid: Instituto Juan de Herrera.

Monsalvo AnTón, José María (2010). Atlas histórico de la España medieval. Madrid: Síntesis.

Montero ReguerA, José (1999). “La Segovia del Cid”. Estudios Segovianos. XLII: 298-324. Segovia: Real Academia de Historia y Arte de San Quirce.

Montero Vallejo, Manuel (1992). El Madrid medieval. Madrid: El Avapies.

Montero Vallejo, Manuel (1996). Historia del urbanismo en España. I. Del Eneolítico a la Baja Edad Media. Madrid: Cátedra.

PASSINI, Jean (1984). Villes medievales du chemin de Saint Jacques de Compostelle. (De Plampelune a Burgos) Paris: Editions Recherche sur les Civilisations.

PASSINI, Jean (2001). La ciudad medieval: De la casa al tejido urbano. Cuenca: Universidad de Castilla la Mancha.

PASSINI, Jean y Ricardo IZQUIERDO BENITO (Coords) (2011). La ciudad medieval. De la casa principal al palacio urbano. Toledo: Universidad Castilla la Mancha.

PÉrez HiguerA, María Teresa (1993). Arquitectura mudéjar en Castilla y León. Valladolid: Junta de Castilla y León. Consejería de Cultura y Turismo.

POËTE, Marcel (2011). Introducción al urbanismo. La evolución de las ciudades: La lección de la Antigüedad. Barcelona: Fundación Caja Arquitectos.

RemOlina SEIVANE, José Miguel. 2006. “Aproximación a la urbanística medieval en Castilla-León: La construcción de los espacios y los tejidos urbanos", en Beatriz ARIZAGA Bolumburu, y Jesús. A. SOlóRZANo TelecheA (Eds.), El espacio urbano en la Europa medieval. Nájera. Encuentros Internacionales del Medievo: 401-414. Logroño: Instituto de Estudios Riojanos. 
REPRESA RODRíGUEZ, Amando (1949). "Notas para el estudio de la ciudad de Segovia en los siglos XII-XIV". Estudios Segovianos I, no 2-3: 273-319. Segovia.

RUIZ DE CASTRO, Garci [1551] (1988). Comentario sobre la primera y segunda población de Segovia. Segovia: Diputación Provincial. (Edición transcrita y anotada por José Antonio Ruiz Hernando).

RUIZ HERNANDO, José Antonio. (1973). “Arquitectura civil de estilo románico en Segovia". Estudios Segovianos. XXV, I, 73: 53-116. Segovia.

RUIZ HERNANDO, José Antonio (1982). Historia del urbanismo en la ciudad de Segovia del siglo XII al XIX. Segovia: Diputación Provincial de Segovia.

RuIZ HeRnANDO, José Antonio (1986). La ciudad de Segovia. Segovia: Ayuntamiento de Segovia.

RUIZ HERNANDO, José Antonio (1988). Arquitectura de ladrillo en la provincia de Segovia. Siglos XII y XIII. Segovia: Diputación Provincial.

RUIZ HERNANDO, José Antonio (2005). “La residencia señorial en Segovia en los siglos XII al XIV", en Xavier BARRAL I ALTET (Dir), Vivir en palacio en la Edad Media. Siglos XII - XV: 81-98. Segovia: Caja Segovia.

RuIZ HernANDO, José Antonio (2007). "El románico civil” en Miguel Ángel GARCía GuineA, y José María PÉREZ GonZÁLEZ. (Dir), Enciclopedia del Románico en Castilla y León. Segovia. Volumen I: 89-201. Aguilar de Campoo: Fundación Santa María la Real.

RUIZ HERNANDO, José Antonio (2008). Iglesias parroquiales de Segovia. Madrid: Instituto Juan de Herrera.

RUIZ HERNANDO, José Antonio (2010). “El Alcázar de Segovia, desde los orígenes al siglo XV", en VVAA. El Alcázar de Segovia. Bicentenario 1808-2008: 45-91. Segovia: Patronato del Alcázar de Segovia.

SÁEZ y ROMERO, Mariano (2009). Facsímil (1918) Las calles de Segovia. Noticias, tradiciones y curiosidades. Sevilla: extramuros SL.

SÁINZ GUERRA, José Luis (1990). La génesis de la plaza en Castilla durante la Edad Media. Valladolid: Colegio Oficial de Arquitectos.

Siguero LlORENTE, Pedro Luis (1997). Significado de los nombres de los pueblos y despoblados de Segovia. Madrid: Gavilán.

TORRES BALBÁs, Leopoldo (1968). “La Edad Media” en VV.AA. Resumen histórico del urbanismo en España. Pp. 67-149, Madrid: I.E.A.L.

TORRES BALBÁS, Leopoldo (1985). Ciudades hispanomusulmanas. Madrid: Instituto hispano árabe de Cultura, Ministerio Asuntos Exteriores. 
Utrero AguAdo, María de los Ángeles (2006). Iglesias tardoantiguas y altomedievales en la Península Ibérica. Madrid: CSIC.

ZAMORA CANElladA, Alonso (1979a) "Excavaciones en el Atrio Norte de San Millán de Segovia. Épocas Céltica y Medieval". Noticiario Arqueológico Hispánico, 6. Madrid: Ministerio de Cultura.

ZAMORA CANElladA, Alonso (1979b). "Sobre el subsuelo de San Millán de Segovia" en Actas del I Congreso Internacional de Estudios Mozárabes de Toledo. Toledo: Instituto de Estudios Visigótico-Mozárabes de San Eugenio.

ZAMORA CANELLADA, Alonso (1994). “Un particular sistema de construcción militar en los albores del siglo XI" en Actas del I Congreso de Castellología Ibérica: 761-781. Palencia: Diputación Provincial de Palencia.

ZAMORA CANELLADA, Alonso (1997). “Algunas reflexiones sobre el siglo X en la provincia de Segovia". Estudios Segovianos, XXXVIII, 413-432.

Zamora CANelladA, Alonso (1998). Museo Zuloaga, Segovia. San Juan de los Caballeros. Segovia: Junta de Castilla y León.

ZAmora CANellada, Alonso y Fernando Vela Cossío (2005). "Paramentos de fortificaciones en la Segovia prerrománica (siglos VII al XI)" en Santiago HuerTa (Ed.) Actas del IV Congreso Nacional de Historia de la Construcción, II: 1137-1154. Madrid: Instituto Juan de Herrera.

ZAMORA CANELlaDA, Alonso (2008). “Fortificaciones en la provincia de Segovia. Hacia un inventario". En Armamento e iconografía en la Antigüedad y la Alta Edad Media: 139-176. Revista Oppidum: Anejo 1. Segovia: IE Universidad.

ZAMORA CANELlADA, Alonso (2010). "A modo de conclusión", en S. MARTíneZ CABALlero, J. SANTIAgo PARDO y A. ZAMORA CANELlADA (coords), Segovia romana II. Gentes y territorio: 411-421. Segovia: Caja Segovia.

ZOZAYA STABEL-HANSEN, Juan (2005a). “¿Poblados? ¿ciudades? ¿campamentos? ¿recintos castrales? en la Marca Media: hacia una tipología", en AlAndalus, país de ciudades. Actas del Congreso. Oropesa (Toledo) del 12 al 14 de marzo de 2003: pp. 23-63. Madrid: Diputación Provincial de Toledo.

ZOZAYA STABEL-HANSEN, Juan (2005b). “Toponimia árabe en el valle del Duero", en Mario JORGE BARROCA e Isabel Cristina FERRERIA FERNANDES (eds.), Musulmano e cristaos entre o Tejo e o Douro. Secs VIII a XIII: 17-42. Palmela: Camara municipal de Palmela. 